\title{
ANÁLISE MULTICRITÉRIO DE PROJETOS DE HABITAÇÃO EM MADEIRA EM NATAL/RN
}

\section{OLIVEIRA, BÁRBARA LAIÍS FELIPE}

Mestre, Universidade Federal Rural do Semi-Árido e barbara.felipe@ufersa.edu.br

\section{PEDRINI, ALDOMAR}

Doutor, Universidade Federal do Rio Grande do Norte e apedrini@ufrnet.br

\section{PINTO, EDNA MOURA}

Doutora, Universidade Federal do Rio Grande do Norte e emourap@ufrnet.br

\section{RESUMO}

A madeira pode ser a melhor alternativa para fomentar a sustentabilidade no meio da construção civil, em detrimento aos materiais convencionais. Esse artigo contribui com essa premissa por meio da avaliação multicritério de dois estudos de caso de habitação em madeira localizados em clima quente e úmido. Os critérios consideram a pré-fabricação, modulação, racionalidade construtiva e a procedência das madeiras, e serviram para orientar as entrevistas com os projetistas das edificações. Os dois casos foram selecionados de acordo com a disponibilidade dos entrevistados e o acesso à informação: Casa Bellini e HabtØ. A partir da análise foi possivel identificar os obstáculos no processo de viabilização dos sistemas construtivos em madeira localmente, considerando as decisões no processo projetual. Os resultados destacam a importância do custo da estrutura, qualidade da madeira (certificada, reflorestada ou tropical), condições de transporte (documentações necessárias, valores e tempo), o impacto ambiental e a relação de custo/benefício.

PALAVRAS-CHAVE: habitações em madeira; pré-fabricação em madeira; projeto em madeira; viabilidade; clima quente úmido.

\section{RESUMEN}

La madera puede ser la mejor alternativa para fomentar la sostenibilidad en el medio de la construcción civil, en detrimento de los materiales convencionales. Este artículo contribuye con esta premisa a través de la evaluación multicriterio de dos estudios de caso de vivienda en madera ubicados en clima cálido y húmedo. Los criterios consideran la prefabricación, modulación, racionalidad constructiva y la procedencia de las maderas, y sirvieron para orientar para orientar las entrevistas con los proyectistas de las edificaciones. Los dos casos fueron seleccionados de acuerdo con la disponibilidad de los entrevistados y el acceso a la información: Casa Bellini y Habt $\varnothing$. A partir del análisis fue posible identificar los obstáculos en el proceso de viabilidad de los sistemas constructivos en madera localmente, considerando las decisiones en el proceso proyectual. Los resultados destacan la importancia del costo de la estructura, calidad de la madera (certificada, reforestada o tropical), condiciones de transporte (documentaciones necesarias, valores y tiempo), el impacto ambiental y la relación de costo / beneficio.

PALABRAS CLAVES: viviendas de madera; prefabricación en madera; diseño de madera; viabilidad; clima cálido húmedo.

\section{ABSTRACT}

Wood may be the best alternative to promote sustainability in the construction area, to the detriment of conventional materials. This article contributes with the multicriteria assessment of two wooden housing case studies at Natal / RN. The criteria concern prefabrication, modulation, constructive rationality and the wood procedence, and served to guide the interviews with the building designers. The cases were selected according to the availability of respondents and information access: Casa Bellini and Habt $\varnothing$. The analyses resulted in the identification of feasibility obstacles of wood building systems locally, based on decisions during the design process. The results emphasized the importance of structure cost, timber quality (certified, reforested or tropical), transport conditions (necessary documentation, values and time), environmental impact and cost/benefit ratio.

KEYWORDS: wooden habitations; prefabricated wood structures; wooden projects; feasibility; humid hot weather.

\section{INTRODUÇÃO}

O uso de sistemas construtivos em madeira é uma das alternativas para desenvolvimento de habitações de baixo impacto ambiental e as madeiras reflorestadas têm sido a opção mais adequada para setor madeireiro, tendo em vista o crescimento acelerado das espécies e a possibilidade de manejo das florestas. Isso permite a perpetuação da produção da madeira, sem a decorrente degradação do equilíbrio ambiental (ESPÍNDOLA, 2010).

Em países do hemisfério norte (Estados Unidos, Canadá, Japão e Europa), a madeira destaca-se como material estrutural e construtivo com qualidades compatíveis com o concreto, o aço e o alumínio. Esses 
locais (geralmente de clima frio) se destacam pelo desenvolvimento de tecnologias subsidiadas por incentivos governamentais que consolidam o processo industrial, assegurando a qualidade da matéria prima com um controle na plantação, o processo industrial de usinagem, beneficiamento do material até o produto final; ou seja, da habitação aos componentes construtivos, mobiliário e utensílios (BITTENCOURT, 1995; MELLO, BITTENCOURT, 2009).

No âmbito nacional, historicamente o uso da madeira na construção civil se deu no oeste paulista e no norte do Paraná e na região Sul com a colonização inglesa, italiana, alemã, japoneses e poloneses. Esse processo de colonização com grandes derrubadas de matas e formação de núcleos urbanos, sítios e fazendas de café, iniciou-se aproximadamente no séc. XIX e XX, e essa cultura ainda permanece nessas regiões (LAROCA, 2002; MEIRELLES et al 2007; ZANI, 2013). Ainda que o Brasil tenha um quadro favorável para o crescimento do setor construtivo em madeira, esse potencial nacional contrasta com a baixa participação das edificações utilizando a matéria prima. Reconhece-se que é decorrência do pouco entendimento das potencialidades do material por parte dos projetistas, uma vez que são necessários requisitos específicos. Atualmente, grande parte da construção civil em madeira adota técnicas inadequadas e insustentáveis, fazendo com que essas construções sejam associadas com a baixa qualidade e com habitações provisórias (MELLO, BITTENCOURT, 2009; ESPÍNDOLA, 2010).

A madeira possui propriedades físicas e mecânicas que podem proporcional conforto térmico, baixo conteúdo de energia, reuso e reciclagem de habitações, se devidamente projetada. Se pré-fabricada, também possibilita um maior controle da qualidade das peças e gestão do processo e mão de obra. Além disso, permite desenvolver, com qualidade, soluções criativas, inovadoras, robustas para projetos arquitetônicos e estruturais (HERZOG, 2001; NEFF, NEUFERT, 2007; BRANCO et al, 2013)

Esse artigo é parte da dissertação de mestrado que trata de edificações de baixo impacto ambiental em madeira para o clima quente e úmido (OLIVEIRA, 2016) $)^{1}$ e utiliza uma abordagem multicritério para avaliar dois estudos de caso de habitações em madeira, localizados em Natal/RN. Os critérios analisados consideram a pré-fabricação, modulação, racionalidade construtiva e a procedência das peças em madeiras. Eles foram aferidos com base na coleta de informações técnicas e entrevistas com os projetistas e proprietários das edificações. Os casos, selecionados de acordo com a disponibilidade dos entrevistados e o acesso a informação, foram: Casa Bellini e HabtØ.

\section{DESENVOLVIMENTO}

A avaliação do uso da madeira deve considerar vários aspectos. Inicialmente, a madeira é um material suscetível à umidade do ambiente. Ao ser exposta em uma atmosfera com pouca umidade, a madeira tende a perder água e no ambiente úmido está propensa a absorção de água. Essa variação influencia diretamente nas propriedades físicas e mecânicas, na secagem e preservação, na durabilidade natural, trabalhabilidade, acabamentos e produtos derivados. O desempenho construtivo do material depende da quantidade de água presente nas suas cavidades e o ambiente em que ela será utilizada (MELO, 2002). Além disso, a densidade da madeira também pode variar de acordo com cada espécie, que influencia a densidade do tronco da árvore. Essa diferença se dá pela diversidade dos tipos de células e proporções de vazios em relação ao tecido lenhoso. Dessa forma, identifica-se a espécie e o comportamento higroscópico nas condições climáticas da implantação do projeto (LAROCA, 2002).

Quanto aos aspectos da arquitetura em madeira, destacam os que facilitam a elaboração e compatibilização de projetos: modulação, pré-fabricação, racionalidade construtiva e a certificação das madeiras. A modulação relaciona dimensões dos materiais e componentes de uma obra, através de medidas modulares organizadas por um reticulado espacial de referência. As medidas que compõem um projeto podem derivar de objetos e situações observadas no mundo real, dos tipos: vãos e subdivisões nas estruturas, necessidades ergonômicas, tamanhos de objetos, carros, mobiliário, pessoas (LUCINI, 2001, apud ESPÍNDOLA 2010).

A necessidade de estabelecer um módulo em um projeto possibilita várias vantagens na execução de elementos em uma composição arquitetônica, além de ser um ponto elementar para solucionar as incompatibilidades construtivas. A prática da modulação traz um melhor aproveitamento da construção, da tecnologia e da produção. Em decorrência disso, há uma maior otimização/aproveitamento do consumo de matérias primas, de energia para produção desses elementos e maior controle dos resíduos provenientes desses processos, o que torna possível organizar o custo total do projeto e mensurar o tempo de conclusão da obra (ROSSO, 1976; GREVEN; BALDUF, 2007).

No Brasil, a NBR 15873:2010 regula o uso da coordenação modular. Fixou-se o módulo básico de 100mm como instrumento de compatibilização de elementos e componentes na construção civil por meio da 
coordenação de dimensões. A norma simplifica as operações da construção e estimula a fabricação versátil de componentes.

Segundo Caldas (2014) existe uma relação entre os conceitos de sustentabilidade elencados por Sachs (2007) e as estratégias utilizadas pelos sistemas estruturais, e reafirma-se essa relação ao compreender que a partir da modulação viabiliza-se o uso de produtos pré-fabricados e industrializados de forma planejada, racional e com menos desperdício. Com o uso da modulação, também é possível utilizar a flexibilidade nos ambientes, nas composições formais e nos layouts das construções. Como exemplo disso, a empresa TecVerde de Curitiba/PR utiliza o Wood Frame em suas construções. Esse sistema utiliza painéis em madeira com placas de gesso fazendo o fechamento interno e externo (Figura 1Erro! Fonte de referência não encontrada.) o que facilita a racionalização da construção pelo uso da modulação. Dessa forma, a empresa destaca o uso desses parâmetros como um diferencial para o cliente, definindo previamente qual será o tempo de execução da obra e o custo.

Figura 1: Composição dos painéis de Wood Frame da TecVerde.

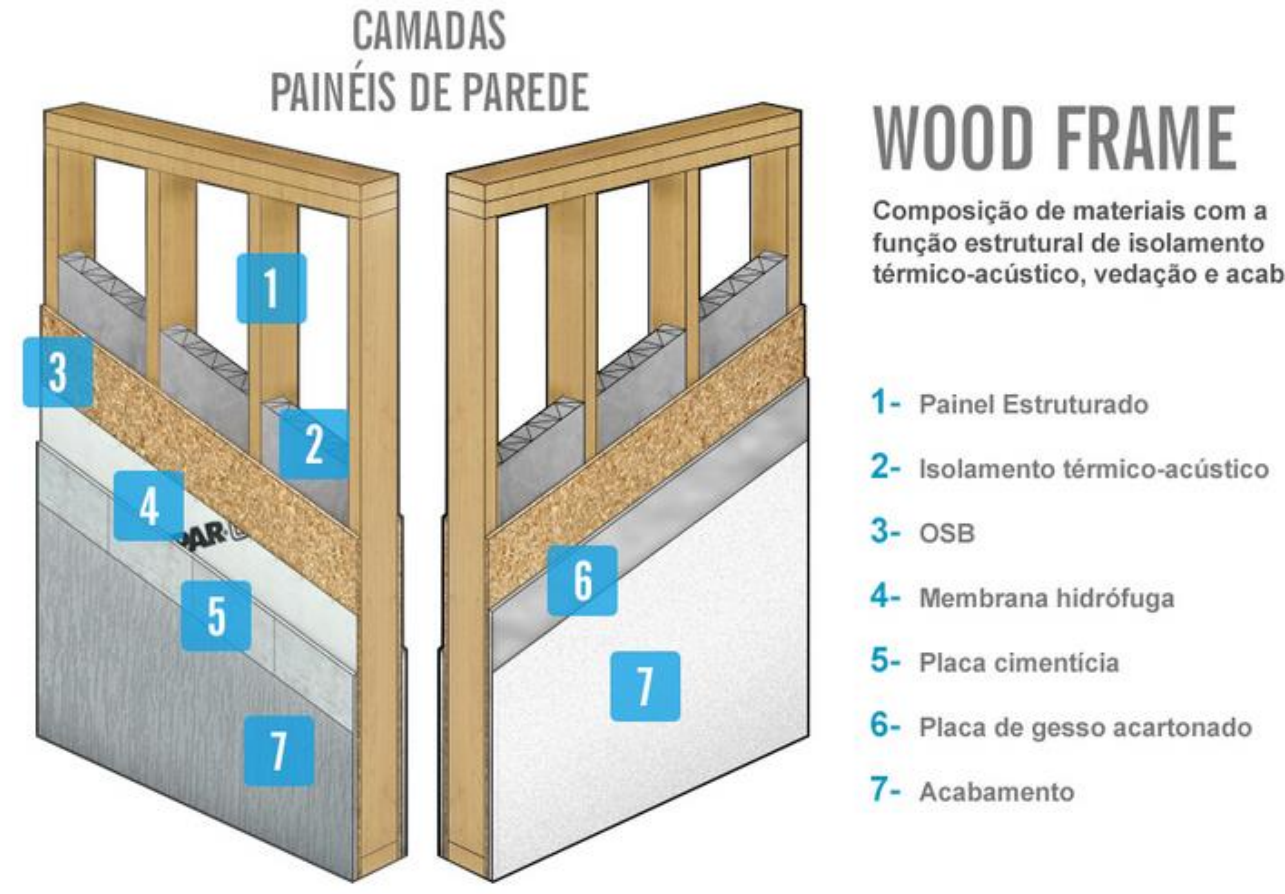

Fonte: TecVerde ${ }^{2}$

A modulação auxilia a racionalização do processo construtivo garantindo a flexibilidade da combinação de elementos e contribuindo para uma maior precisão na definição e alcance de medidas. Coopera também para o aumento da repetição de componentes, o que facilita a produção em série, ao fixar uma medida básica com relação à qual as demais devem ser múltiplas ou mesmo submúltiplas, o que limita as variações dimensionais para um mesmo elemento construtivo (CARVALHO; TAVARES, 2015).

Rosso (1980) destaca que a racionalidade construtiva age contra os desperdícios de materiais e utiliza de forma mais eficiente o investimento na aplicação de princípios de planejamento, organização e gestão, visando eliminar a casualidade nas decisões e incrementar a produtividade do processo. Esse conceito deve incidir sobre a edificação desde o processo de concepção até o produto final.

A partir do uso da racionalidade é possível maximizar e controlar os custos de uma construção no processo de industrialização. Assim, o setor construtivo desenvolve uma nova tendência para a fabricação de casas, onde o uso de elementos pré-fabricados que contemplam as normas e os conceitos de modulação são os elementos mais viáveis para as construções de baixo consumo (GREVEN; BALDUF, 2007).

Trigo (1978), Espíndola (2010) e Greven e Balduf (2007) concordam que o processo de industrialização, ao ser inserido no modo de construir convencional, deve respeitar as condições de habitabilidade, funcionalidade, durabilidade, segurança e acabamento, ademais devem apresentar características relacionadas à produtividade, construtividade, baixo custo e desempenho ambiental que são parâmetros importantes para os profissionais da área. $\mathrm{O}$ incentivo à industrialização abrevia o processo de concepção e 
implantação de uma edificação, o que por vezes é uma alternativa mais rápida no processo de ocupar um terreno de forma provisória ou por um curto espaço de tempo.

A industrialização se propõe a buscar a economia na forma macro, compatibilização e otimização da qualidade, quantidade e o custo. Essa meta resulta em uma racional aplicação dos recursos, onde os desperdícios são descartados e há um aumento da eficiência da produção, mão de obra e equipamento. Essa relação de eficiência é medida pela produtividade, ou seja, pela relação insumos/produtos. Quanto menor essa relação, maior a produtividade (ROSSO, 1976).

O detalhamento e a especificação do projeto são peças primordiais para uma implantação precisa, e sem custos posteriores com reparo. Se alguma peça tiver dimensões alteradas será necessário atrasar a montagem para redimensiona-la e se for com comprimento inferior é possível que seja descartada. Desse modo, necessita-se que haja uma minúcia no desenvolvimento do projeto, no qual o detalhe construtivo será parte da especificação para a execução da construção; a partir disso, será possível compatibilizar as diversas peças (e elementos) do sistema construtivo da edificação (BITTENCOURT, 1995).

Quanto à origem da madeira no Brasil, a forma de extração e comercialização, por vezes é ilegal. Desse modo, a certificação do material é um fator que necessita ser analisado. A certificação florestal é um requisito necessário para comprovar a origem e o manejo florestal em que a madeira foi submetida. No entanto, a certificação no país é um processo voluntario realizada através de uma organização independente; essa, verifica os cumprimentos das questões ambientais, econômicas e sociais sob as leis nacionais vigentes e acordos internacionais. No mundo, existem diversos tipos de selos que atestam a qualidade da madeira, dentre eles: Forest Stewardship Council (FSC), Programme for the Endorsement of Forest Certification Schemes (PEFC), Canadian Standard Association (CSA) e o Programa Brasileiro de Certificação Florestal (CERFLoR). De acordo com a ABRAF (2013), os sistemas de controle que possuem maior destaque no Brasil são o FSC e o CERFLoR/PEFC.

No Brasil, em 2012, aproximadamente, 7,2 milhões de hectares de florestas foram certificadas pelo Selo FSC e 1,3 milhão de hectares certificadas pelo Selo da CERFLoR, representando 2,1\% do total mundial. Destaca-se que nesse número existem empresas certificadas pelos os dois selos em questão (ABRAF, 2013). Nesse campo, Soares et al. (2011) informam que o pequeno número de certificação verificado ocorre pela falta de incentivos governamentais para adesão a esse processo, devido aos difíceis padrões a serem cumpridos, ao elevado custo da certificação, à baixa conscientização e à pouca exigência do mercado, ao que se alia o número reduzido de certificadoras. No entanto é preciso ressaltar que as empresas que aderem à legislação possuem vantagens, tais como: promoção do manejo sustentável, mais acesso a mercados competitivos para produtos florestais madeireiros e não-madeireiros, preços diferenciados, melhor imagem institucional e melhor acesso a fontes de financiamento.

\section{MÉTODO}

Os procedimentos metodológicos que proporcionaram a investigação apresentada nesse artigo consistiram na avaliação de dois estudos de casos selecionados a partir da dissertação de mestrado de Oliveira (2016) ${ }^{1}$ e correspondentes a casas de madeira projetadas para Natal-RN, as quais estão próximas à costa litorânea.

Com a premissa de proporcionar uma análise do geral para o particular (método dedutivo), a investigação tomou como critérios analíticos: pré-fabricação, modulação, racionalidade construtiva e certificação das madeiras. Tais critérios foram definidos a partir da revisão bibliográfica e organizados com o objetivo de comparar duas propostas de construções em madeira elaboradas para uma mesma cidade, ressaltando as diferenças no processo projetual e no desenvolvimento da obra.

As informações analisadas foram obtidas por meio de plantas arquitetônicas e estruturais, visitas no local da construção, acompanhamento de processos e entrevistas aos projetistas e proprietários. A coleta de dados foi guiada pelos multicritérios (pré-fabricação, modulação, racionalidade construtiva e certificação das madeiras) embasados no referencial desse trabalho.

Os resultados estão organizados em duas partes: apresentação dos estudos de caso e análise multicritério. Os estudos de caso em questão foram expostos de forma sucinta com plantas arquitetônicas e imagens, posteriormente foi construída a análise por meio de comparativos entre os dois casos. 


\section{RESULTADOS}

\section{Estudo de caso 1: casa Bellini}

A casa Bellini foi projetada pelos arquitetos da "Modo arquitetura + design" de Porto Alegre/RS para um casal com três filhos na cidade de Natal. Localiza-se no condomínio fechado na praia de Cotovelo/RN em um terreno de $360 \mathrm{~m}^{2}$ e possui três andares que distribuem: a sala de estar / jantar, cozinha americana, cinco quartos, lavabo, três banheiros, despensa, lavanderia, dois closets, escritório, jardim interno e sala de yoga, resultando em $258 \mathrm{~m}^{2}$ de área construída (Figura 2). A Figura $2 \mathrm{~A}$ mostra a planta baixa do andar térreo e Figura 2B representa a planta do primeiro andar.

Figura 2: Plantas baixa da Casa Bellini (sem escala).

A

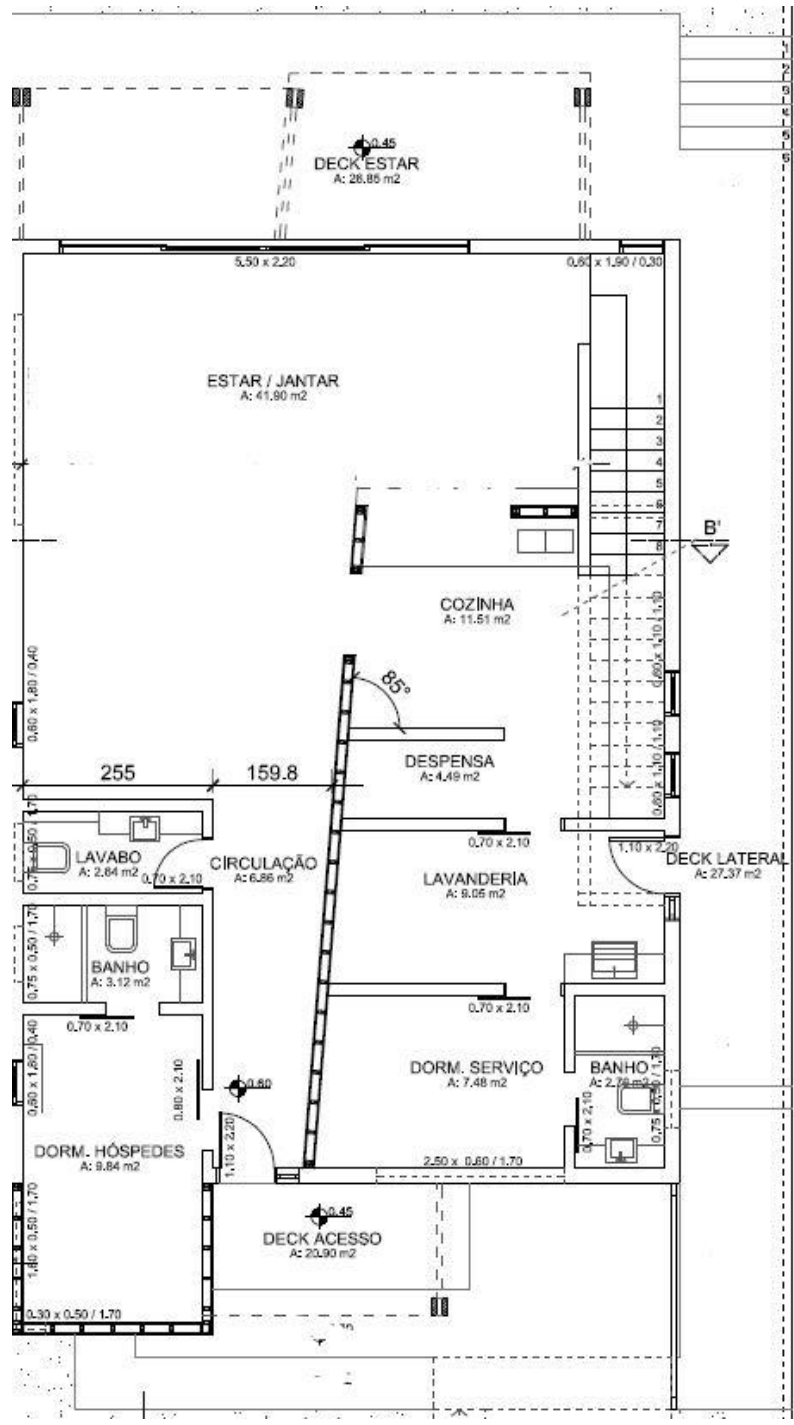

B

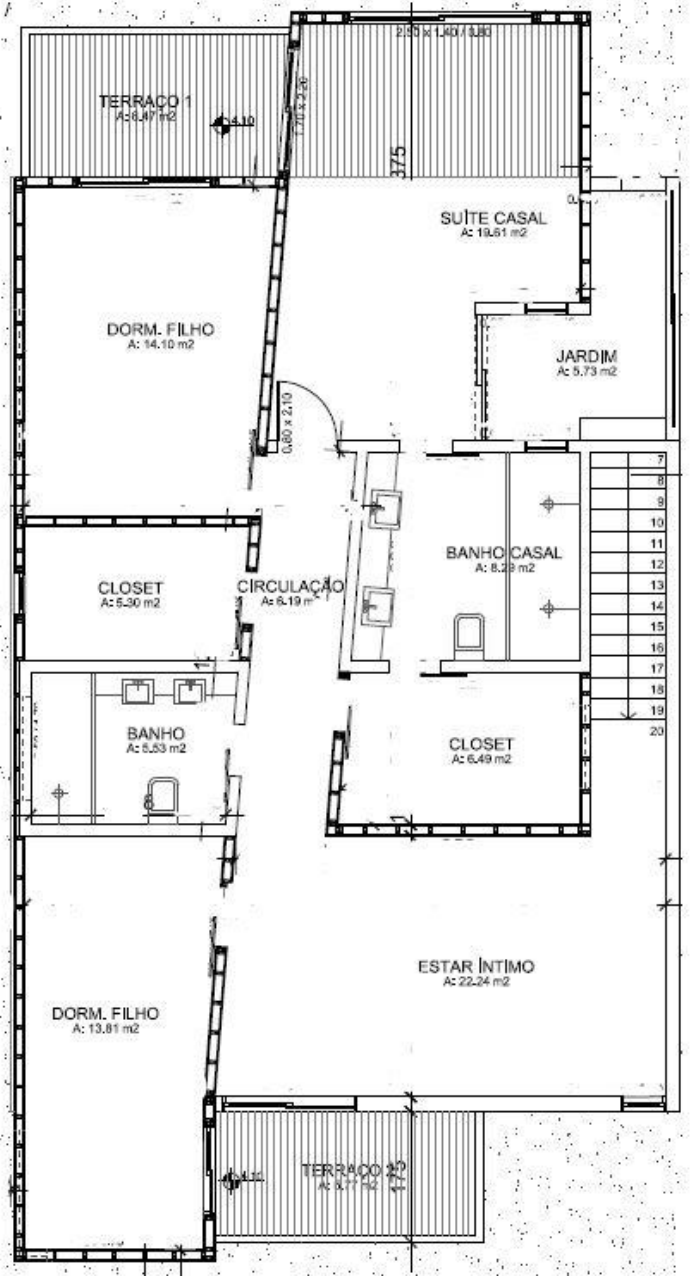

Fonte: Oliveira (2016).

A proposta da residência foi baseada em outro imóvel do casal existente em Fernando de Noronha/PE e projetada pelos mesmos arquitetos. A escolha por madeira decorre da experiência do proprietário com os aspectos rapidez, montagem seca, aspectos sensoriais e sustentáveis. Em entrevista, o proprietário, Claudio Bellini, conta que a diretriz principal do projeto foi a utilização de madeira reflorestada tratada que não possuísse impregnação por metais pesados. Desse modo, a madeira utilizada possui tratamento em CA-C (Cobre Azoles), sendo a obra pioneira no estado do Rio Grande do Norte. O sistema construtivo é misto com o uso de alvenaria e Wood Frame, além de possuir vigas em MLC (madeira laminada colada) para sustentar a cobertura. A Figura 3 mostra alguns espaços da residência, tais quais na Figura 3 A: Sala de estar íntima; Figura 3B: Quarto no andar superior (destaque para a viga em MLC); Figura 3C: Suíte no andar superior. 
A

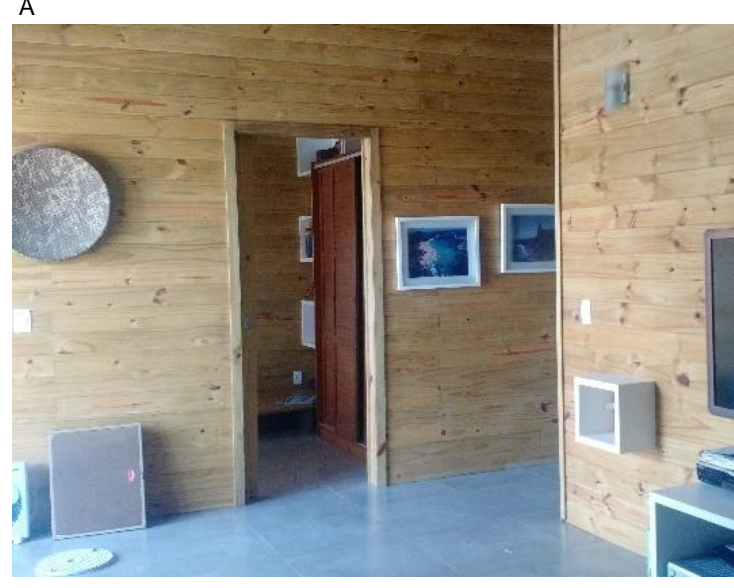

Figura 3: Fotos da Casa Bellini

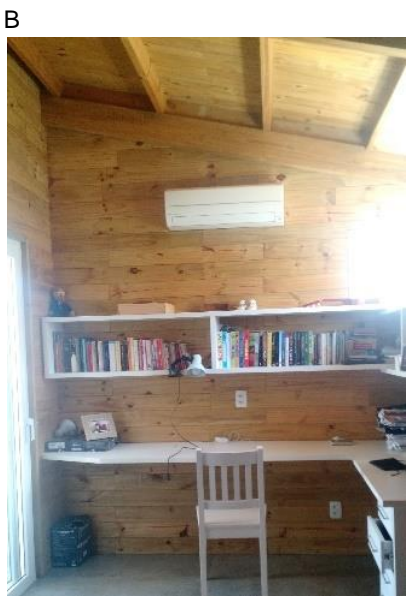

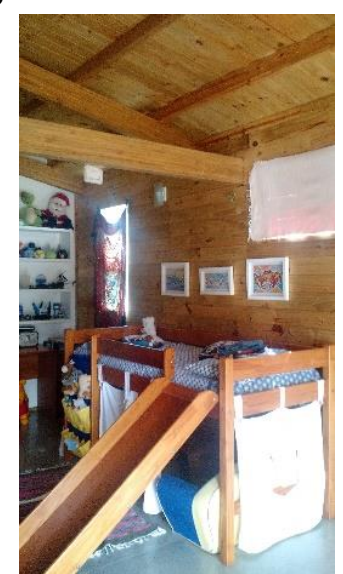

Fonte: Oliveira (2016).

$\mathrm{Na}$ edificação, a parte em alvenaria corresponde a área molhada, quase todo o andar térreo e a parte da caixa d'água. A parte em madeira abriga o andar superior com os quartos e a sala íntima. Os proprietários contam que intencionavam, originalmente, apenas um volume em alvenaria e a casa em madeira apoiada sobre ele. Os projetistas os convenceram a ter mais áreas em alvenaria e menos em madeira, como mostra a maquete (Figura 4) e apresenta madeira na parte mais escura da edificação e alvenaria na parte em branco.

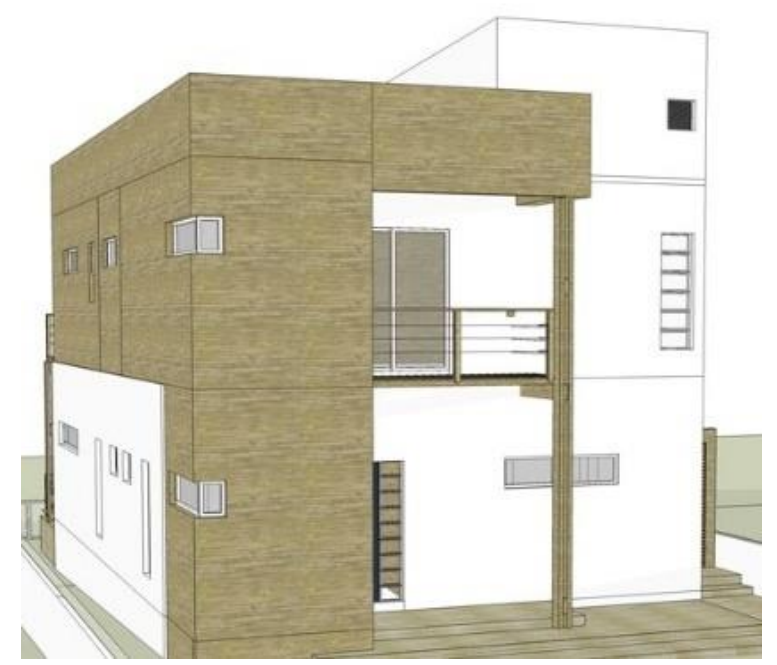

Figura 4: Maquete da Casa Bellini: Figura 4a) vista frontal e B) vista posterior

B

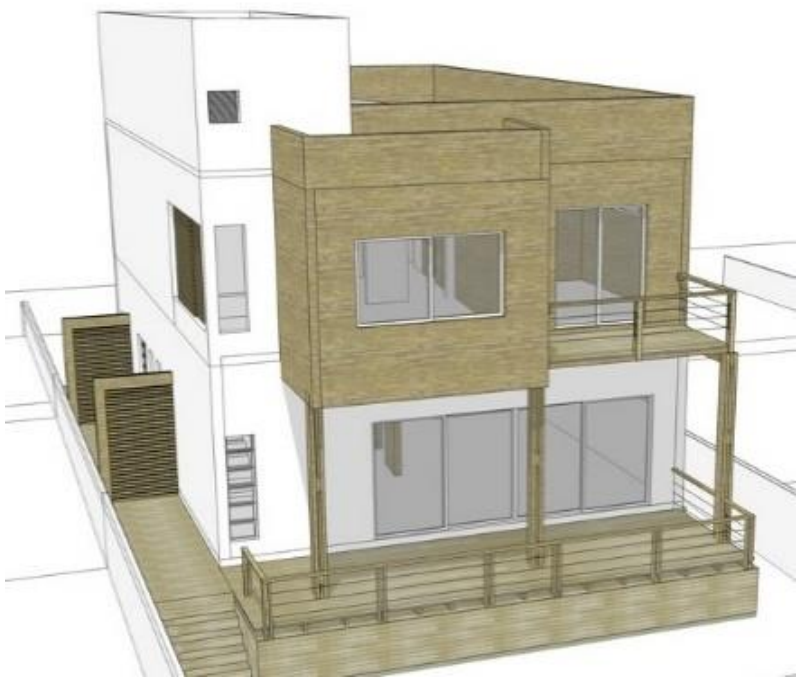

Fonte: Oliveira (2016).

\section{Estudo de caso 2: casa Habtø}

O caso 02 foi projetado pelos arquitetos do Edifício Eficiente para o engenheiro mecânico Aldomar Pedrini. O projeto delineou-se a partir da premissa de uma edificação com 'zero' consumo energético e baixo impacto ambiental (origem do nome HabtØ).

O projeto é definido por três blocos separados e com usos distintos: um estúdio, uma residência (duplex) e um anexo (Figura 5). Nesse estudo de caso considerou-se apenas o módulo central para a análise, que está em processo de construção desde de 2015. Ele é composto por dois pavimentos: no andar térreo (ver planta baixa -

Figura 6) há a sala, cozinha, banheiro, área de serviço; no andar superior encontra-se o quarto (planta baixa

Figura 7). 
A edificação foi projetada tendo como premissas: uso da ventilação e iluminação natural, estrutura aparente, sombreamento dos ambientes, utilização de sistemas construtivos leves e refletores, sistemas de reuso de água, utilização de espécies nativas no paisagismo e uso de energia solar (Figura 8).

Figura 5: Projeto completo da HabtØ

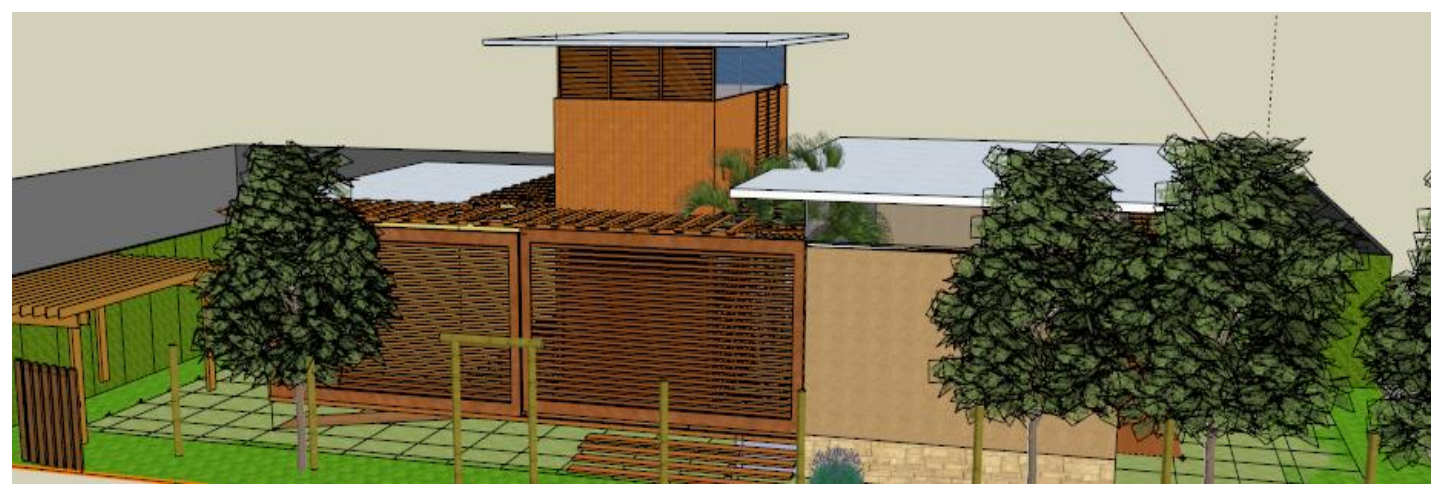

Fonte: Oliveira (2016)
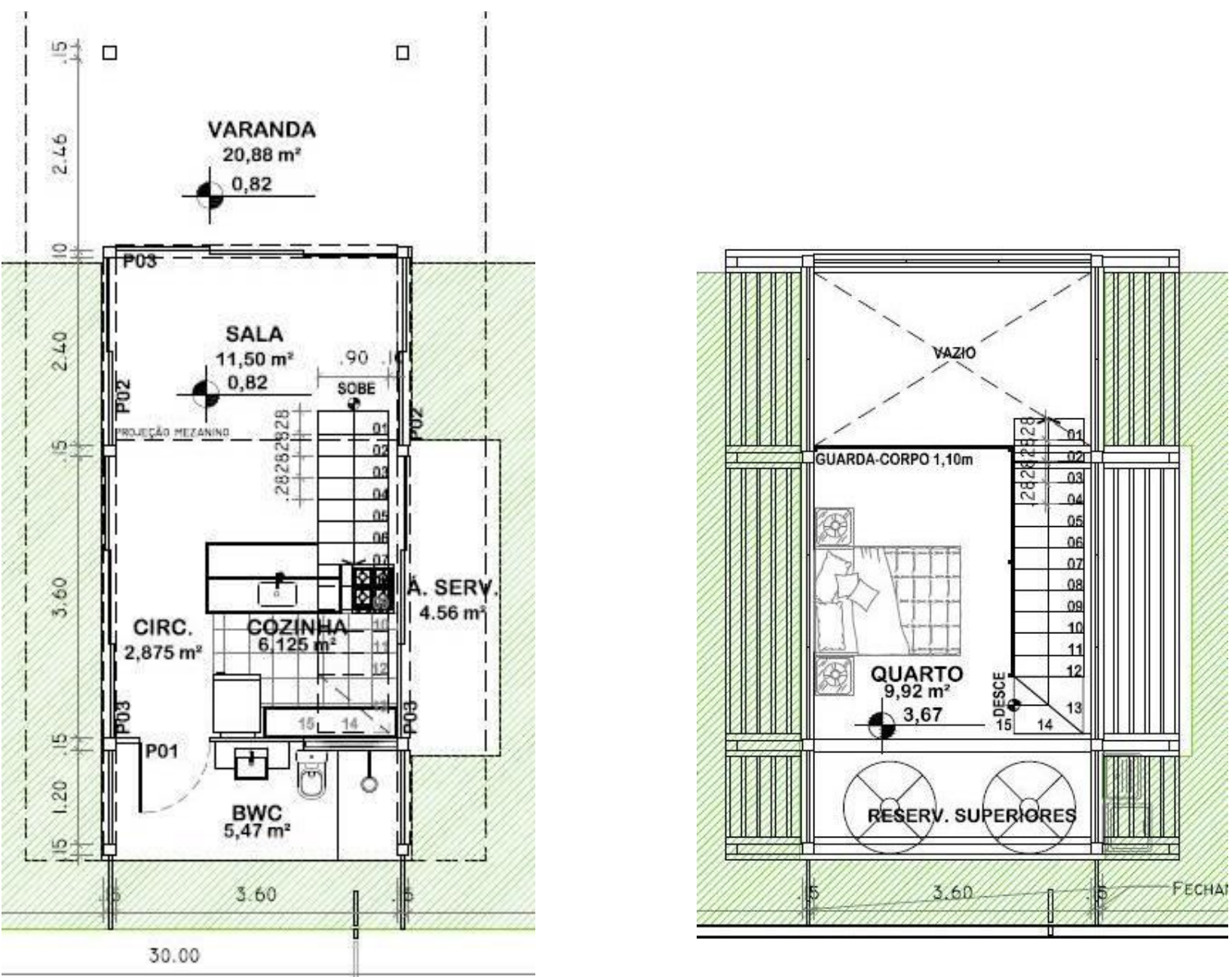

Fonte: Oliveira (2016). 
Figura 8: Módulo central do HabtØ.
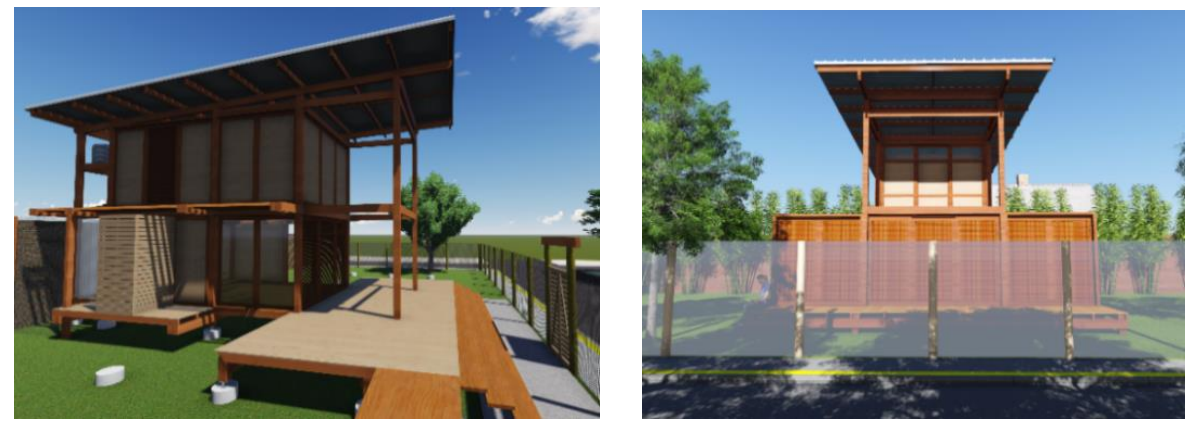

Fonte: Oliveira (2016).

\section{Análise multicritério}

A fim de viabilizar as edificações, ambos os construtores buscaram no mercado de Natal, mão de obra e madeira certificadas e reflorestadas disponíveis. No caso 01, construído entre os anos de 2014 e 2015, o mercado não possuía peças em Pinus CA-C e nem usinagem possível para fabricação do sistema Wood Frame. Desse modo, o proprietário e construtor da casa encomendou as peças pré-fabricadas do Uruguai e as trouxe em dois containers via transporte marítimo (isso foi possível pelo alto volume de peças).

Durante a construção, um container serviu como depósito para estocagem das ferramentas e materiais, e o outro foi revestido termicamente, para que pudesse servir de escritório (do proprietário) no processo de construção. O construtor explica que, apesar de ter trazido as peças de fora, a relação custo e benefício foi favorável. A estrutura encomendada chegou ao local com as peças beneficiadas e numeradas. A equipe de carpinteiros necessitou apenas fazer a pré-montagem e pequenos ajustes (Figura 9).

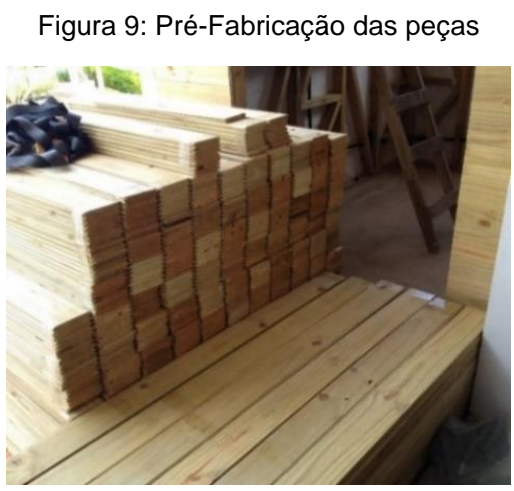

Fonte: Oliveira (2016)

Além do tratamento com a espécie de madeira, a fixação das tábuas foi feita com prego de poliuretano (Figura 10 e Figura 11) e a edificação foi suspensa por sapatas de concreto que isolam os pilares de madeira do solo (Figura 12).

A não disponibilidade de mão de obra local levou o proprietário a trazer carpinteiros do Rio Grande do Sul e a montar uma serraria completa, que também serviu para a fabricação e remodelação dos próprios móveis.

Figura 10: Fixação das peças de Wood Frame

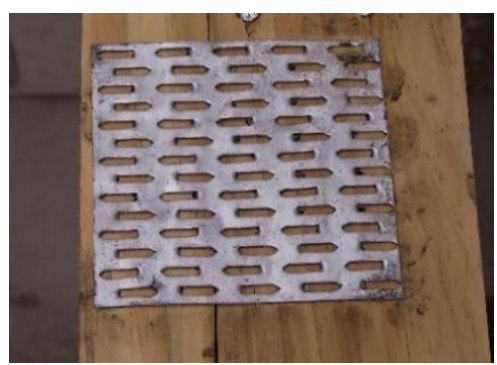

Figura 11: Prego em poliuretano

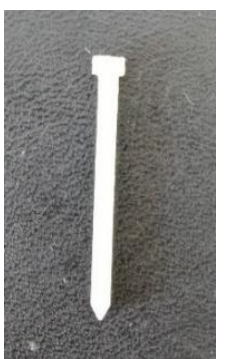

Fonte: Oliveira (2016).
Figura 12: Pilares em madeira com sapata em concreto

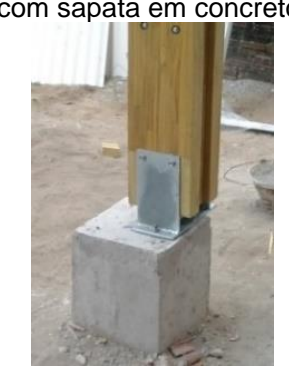


No estudo de caso 02, foram contatadas todas as madeireiras listadas no catálogo da FSC (Forest Stewardship Counci) e CeFlor (Programa Brasileiro de Certificação Florestal), para entrega do produto em Natal. O alto custo do frete rodoviário, a burocracia decorrente da necessidade do D.O.F (Documento de Origem Florestal), a falta de transportadora especializada no manuseio de peças, a impossibilidade de reposição ou troca de peças inviabilizaram a aquisição. Caso fosse viável, seria necessário considerar a energia embutida com o transporte. O transporte marítimo não se mostrou viável porque a quantidade de peças era insuficiente para preencher um container. Também foi constatado a carência local de projetistas de estruturas em madeira. O projeto estrutural foi encomendado à Carpinteria/SP para que privilegiasse um sistema simplificado de montagem e pouca dependência de mão de obra especializada. A madeira utilizada foi a Maçaranduba e com algumas peças em Jatobá, compradas em Natal. As peças entregues pela madeireira precisaram de beneficiamento posterior em serraria para desempenamento, desengrosso e dimensionamento das peças, conforme o projeto estrutural. Esse processo durou cerca de 6 meses e acrescentou cerca de $20 \%$ no custo da estrutura devido a compra adicional e reposição das peças inadequadas, e o processo de usinagem (Figura 13 e Figura 14).
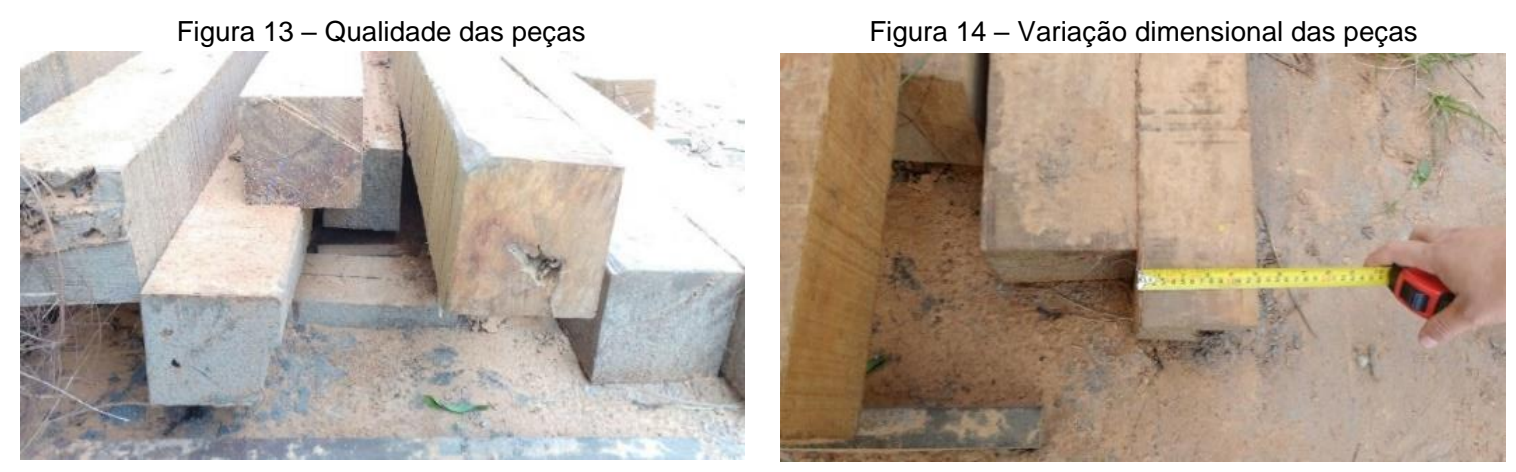

Fonte: Oliveira, 2016.

O projeto estrutural do caso 02 , utiliza conectores metálicos e encaixes específicos para maior durabilidade e resistência à maresia/umidade de Natal. Não foi encontrada mão de obra local e optou-se por uma equipe de São Miguel do Gostoso (102km da capital), que demonstrou interesse em aprender o processo de montagem.

A análise da modulação empregou as plantas, relacionando as medidas dos ambientes com uma malha modular comum. Desse modo, na casa Bellini não foi considerado a modulação impostas pelos marcos de Wood Frame. Logo, verificou-se que os ambientes não possuem modulação, muitas vezes as paredes do andar térreo não correspondem as paredes do andar superior. E Isso, inviabilizou a ideia inicial do proprietário, de colocar no corredor central do andar superior da edificação "visores", para que pudessem observar o andar térreo. No entanto, na Habtø determinou-se que a malha modular seria de 1,20m; esse critério perdurou em toda a concepção projetual e no projeto arquitetônico e estrutural (Figura 15).

Figura 15 - Modulação do projeto.

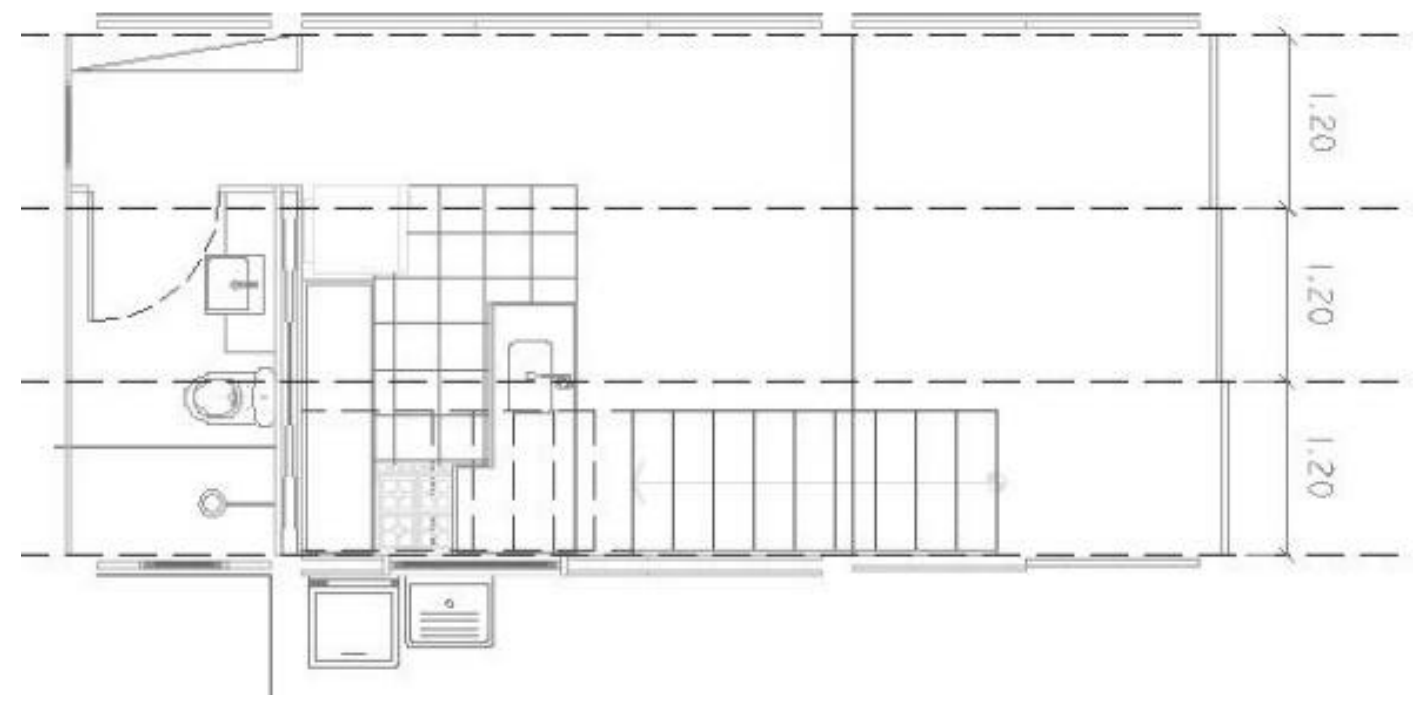

Fonte: Oliveira, 2016. 
Quanto à racionalização construtiva, o caso 01 conseguiu utilizar todas as sobras proveniente dos ajustes das peças para a confecção de móveis a serem colocados na própria residência, tendo produzido mesas, estantes e banquinhos, além de remodelar outros elementos do mobiliário (Figura 16Erro! Fonte de referência não encontrada.).

Figura 16 - Produção de móveis com a madeira restante

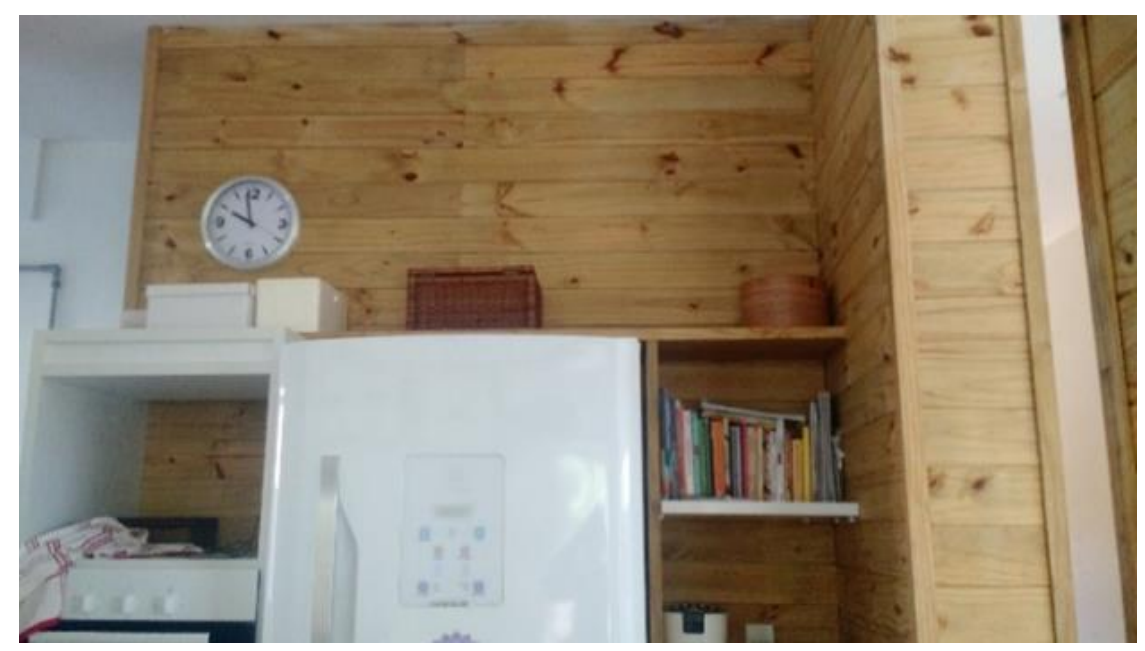

Fonte: Oliveira, 2016.

No caso 02 aparentemente não houve desperdício de madeira, embora tenha havido necessidade de aparelhamento das peças, com consequente aumento de custo e tempo, além de desperdício no tratamento das peças devido à seleção e manipulação inadequada de peças.

A inexistência de madeireiras certificadas localmente fez com que no Caso 01 a madeira fosse trazida do Uruguai e, no Caso 02, a madeira não tenha apresentado certificação.

O custo do Caso 01 foi agravado pelo largo uso de ferragem e concreto na fundação devido ao alto pédireito, grandes vãos e terreno arenoso (dunas de areia). Segundo o calculista, não foi possível utilizar uma fundação mais leve. O custo da mão de obra de construção também foi alta, pois demandou três a cinco pessoas durante um ano. O custo da madeira correspondeu a aproximadamente $22,5 \%$ do valor total da obra, e $\mathrm{R} \$ 1025,00 / \mathrm{m}^{2}$, considerando a aquisição em dólar e pagamento de impostos.

O custo da Caso 02 é incompleto e corresponde a $\mathrm{R} \$ 500,00 / \mathrm{m}^{2}$, considerando que a construção está em andamento e apenas foram finalizadas a fundação e a estrutura em madeira.

\section{CONCLUSÕES}

Os dois estudos de caso confirmam que a madeira é um material com potencial de uso na construção de habitações de baixo impacto ambiental. As vantagens são a possibilidade de ser reciclável, de fácil maleabilidade e por necessitar de baixo conteúdo de energia para a sua produção. Além disso, é um material leve e compatível com clima quente e úmido, capaz de ser utilizado para sombreamento e para grandes aberturas, o que facilita a ventilação natural. A madeira também permite o uso da modulação, préfabricação e racionalidade construtiva nas peças e na planta estrutural e arquitetônica. Entretanto a distância dos principais centros produtivos de madeira tratada do Brasil (a partir de 3.300km) e a falta de mão de obra especializada podem inviabilizar o custo, a exequibilidade e até mesmo reduzir as vantagens quanto à sustentabilidade do empreendimento.

A partir da análise dos critérios nos estudos de caso foi possível identificar os critérios de maior relevância a serem incorporados no processo projetual e os menos viáveis, que não dependem da capacidade do projetista. Os critérios de "modulação", racionalidade construtiva" são viáveis de serem incorporados no processo projetual, uma vez que dependem da habilidade do projetista em incluir esses aspectos no projeto arquitetônico, adaptá-los ao terreno e clima da região de implantação. Os critérios com menor interação são os que dependem de terceiros, no caso: do setor industrial madeireiro e da mão de obra local. Não há logística e nem custo viável para entrega de peças pré-fabricadas em madeira. Assim, os critérios de "préfabricação" e "procedência das madeiras" são prejudicados pela falta de industrialização na região.

Conclui-se que a logística é o principal impedimento à execução de edificações em madeira na região, porque deve-se considerar a disponibilidade da madeira, a integridade do produto e possível reposição do 
material. A indisponibilidade do mercado para aparelhar e beneficiar as peças disponíveis localmente requer um tratamento adicional e podem aumentar cerca de $20 \%$ no custo das estruturas. O frete também é um fator proibitivo pois, para ser viável é necessário um grande volume de peças em madeira para ser deslocado por via marítima em containers ou por rodovias.

Verifica-se, ainda, no mercado natalense, carência de madeiras confiáveis quanto ao procedimento, uma vez que a maior parte das madeiras são trazidas do norte do país e estão suscetíveis às irregularidades de extração. Portanto, na área em estudo, embora observe-se que há muitas potencialidades para o desenvolvimento da arquitetura em madeira, o investimento no setor industrial é pouco, condição relacionada à distância com relação aos centros fornecedores e à falta de interesse do mercado em se modificar. Por sua vez, o fluxo turístico e a paisagem natural da cidade do Natal corroboram para o surgimento de uma arquitetura mais leve, que deveria ser mais explorada pelos projetistas e pelo setor comercial.

\section{REFERÊNCIAS}

ASSOCIAÇÃO BRASILEIRA DE PRODUTORES DE FLORESTAS PLANTADAS (ABRAF). Anuário estatístico da ABRAF 2013: ano base 2012. Brasília: 2013.

ASSOCIAÇÃO BRASILEIRA DE NORMAS TÉCNICAS - ABNT. NBR 15873: Coordenação modular para edificações. Rio de Janeiro: 2010.

BITTENCOURT, R. M. Concepção Arquitetônica da Habitação em Madeira. Tese (Doutorado). Programa de Pósgraduação em Engenharia Civil. Universidade de São Paulo, São Carlos, 1995.

BRANCO, J.M., CRUZ H., LOURENÇO, P.B., NUNES L. (Eds.). Casas em madeira. Da tradição aos novos desafios. Casas em Madeira: Seminário. Lisboa: Universidade do Minho, 2013. 75-86.

CALDAS, M. P. G. Sobre formas e processos: projeto de um condomínio de casas a partir de princípios da gramática da forma. Dissertação (Mestrado). Programa de Pós-graduação em Arquitetura e Urbanismo. Universidade Federal do Rio Grande do Norte, Natal, 2014.

CARVALHO, A.P.A; TAVARES, I. G. Modulação no Projeto Arquitetônico de Estabelecimentos Assistenciais de Saúde: o caso dos Hospitais SARAH. Disponível em: <bvsms.saude.gov.br/bvs/publicacoes/modulacao_hospitais_sarah.pdf>. Acesso em: 01 jul. 2015.

ESPÍNDOLA, L. da R. Habitação de interesse social em madeira conforme os princípios de coordenação modular e conectividade. Dissertação (Mestrado). Programa de Pós-graduação em Engenharia Civil. Universidade Federal de Santa Catarina, Florianópolis, 2010.

FONTENELLE, M. R. A abordagem multicritério na concepção arquitetônica: um estudo sobre as aberturas laterais em edifício de escritórios no Rio de Janeiro. Dissertação (Mestrado). Programa de Pós-graduação em Arquitetura. Universidade Federal do Rio de Janeiro, Rio de Janeiro, 2012.

GREVEN, A. H.; BALDAUF, A. S. F. Introdução à coordenação modular na construção no Brasil: uma abordagem atualizada. Porto Alegre: Antac, 2007.

HERZOG, T. ¿Porqué la madera? Revista Tectônica, 13 (2 ) - Estructuras de madeira. 2001.

LAROCA, C. Habitação social em madeira: uma alternativa viável. Dissertação (Mestrado). Programa de Pós Graduação em Engenharia Florestal, Escola de Ciências Agrárias. Universidade Federal do Paraná, Curitiba, 2002.

MEIRELLES, C. R. M.; DINIS, H.; SEGALL, M. L.; SANT'ANNA, S. S. Considerações sobre o uso da madeira no Brasil em construções habitacionais. III Fórum de pesquisa FAU Mackenzie. São Paulo: 2007.

MELLO, R. L. Projetar em madeira: uma nova abordagem. Dissertação (Mestrado) Programa de Pós-graduação Arquitetura e Urbanismo. Universidade de Brasília, Brasília, 2007.

MELLO, R. L.; BITTENCOURT, R. M.; Projetar Em Madeira: IV PROJETAR - Projeto como investigação: ensino, pesquisa e prática. São Paulo: Ed. Mackenzie, 2009.

NEFF, L.; NEUFERT, P. Casa Apartamento Jardim: Projetar com conhecimento, construir corretamente. Lisboa: Gustavo Gili, 2007.

OLIVEIRA, B. L. F. Edificações de baixo impacto ambiental em madeira para o clima quente e úmido. Dissertação (Mestrado). Programa de Pós-Graduação em Arquitetura e Urbanismo (PPGAU). Universidade Federal do Rio Grande do Norte, 2016.

ROSSO, T. Teoria e Prática da Coordenação Modular. São Paulo: FAUUSP, 1976.

SACHS, I. Rumo à ecossocioeconomia: teoria e pratica do desenvolvimento. São Paulo: Cortez, 2007. 
SOARES, N. S.; MOURA, A.D.; SILVA, M. L.; REZENDE, A.M. Dificuldades para a Certificação Florestal no Brasil. Texto Técnico, outubro/2011. Disponível em: <ciflorestas.com.br>. Acesso em: 04 mar. 2015.

TRIGO, J. T. Tecnologias da construção de habitação. Memória № 507. Lisboa: Laboratório Nacional de Engenharia Civil, 1978.

. Racionalização da construção. São Paulo: FAUUSP, 1980.

ZANI, A. C. Arquitetura em madeira [Livro eletrônico]. Londrina: EdUEL, 2013.

\section{NOTAS}

${ }^{1}$ Dissertação de mestrado defendida pela primeira autora desse artigo, com orientação e co-orientação, da terceira e do segundo autores, respectivamente.

${ }^{2}$ Disponível em http://www.tecverde.com.br/sistema-construtivo/, acesso em 1 de outubro de 2017.

NOTA DO EDITOR (*) O conteúdo do artigo e as imagens nele publicadas são de responsabilidade do(s) autor(es). 